\title{
Phase Decomposition of $\gamma$-U (bcc) in U-10 wt.\% Mo Fuel Alloy during Hot Isostatic Pressing of Monolithic Fuel Plate
}

\author{
Y. Park, N. Eriksson, R. Newell, D. D. Keiser, Jr. Y. H. Sohn \\ ${ }^{1}$ Department of Materials Science and Engineering and \\ Advanced Materials Processing and Analysis Center \\ University of Central Florida, Orlando, FL 32816, USA \\ ${ }^{2}$ Idaho National Laboratory \\ PO Box 1625, Idaho Falls, ID 83401, USA
}




\begin{abstract}
Eutectoid decomposition of $\gamma$-phase (cI2) into $\alpha$-phase (oC4) and $\gamma^{\prime}$-phase (tI6 ) during the hot isostatic pressing (HIP) of the U-10 wt.\% Mo (U10Mo) alloy was investigated using monolithic fuel plate samples consisting of U10Mo fuel alloy, Zr diffusion barrier and AA6061 cladding. The decomposition of the $\gamma$-phase was observed because the HIP process is carried out near the eutectoid temperature, $555^{\circ} \mathrm{C}$. Initially, a cellular structure, consisting of $\gamma^{\prime}$-phase surrounded by $\alpha$-phase, developed from the destabilization of the $\gamma$-phase. The cellular structure further developed into an alternating lamellar structure of $\alpha$ - and $\gamma^{\prime}$-phases. Using scanning electron microscopy and transmission electron microscopy, qualitative and quantitative microstructural analyses were carried out to identify the phase constituents, and elucidate the microstructural development based on time-temperature-transformation diagram of the U10Mo alloy. The destabilization of $\gamma$-phase into $\alpha$ - and $\gamma^{\prime}$-phases would be minimized when HIP process was carried out with rapid ramping/cooling rate and dwell temperature higher than $560^{\circ} \mathrm{C}$.
\end{abstract}




\section{Introduction}

The replacement of high-enriched uranium (HEU) fuel with low-enriched uranium (LEU) fuel is the primary goal of Materials Management and Minimization Reactor Conversion (MMMRC) program, also known as Reduced Enrichment for Research and Test Reactor (RERTR) program [1-4]. Uranium based metallic fuel has garnered heavy consideration based on several advantageous properties, including high fissionable density, high thermal conductivity and good compatibility with cladding materials.

Monolithic design using U-10 wt.\%Mo (U10Mo) fuel alloy is being developed to achieve a higher uranium density for high flux reactors, because of high fissionable density and excellent irradiation behavior [5-7]. The monolithic fuel plates are fabricated via hot isostatic pressing (HIP) in order to encase the fuel plate foil in an Al-alloy based cladding. A Zr diffusion barrier is typically placed between the U10Mo fuel alloy and Al-alloy cladding to prevent interaction between the fuel and cladding. Previously, microstructure resulting from the interdiffusion and solid-state reaction between different constituents of the fuel plate was reported [8-13]. In addition, within the fuel alloy, Meyer et al. [11] reported the presence of "chemical banding" with inhomogeneous Mo content within the fuel alloy, and Jue et al. [12] identified $\gamma$-phase decomposed regions consisting of $\alpha$ and $\gamma^{\prime}$ phases due to heat treatment near the eutectoid temperature. The low-Mo ( 5 wt.\%) and high-Mo ( 13 wt.\%) phases were assumed as $\alpha$ and $\gamma^{\prime}$, respectively [12]. In this study, decomposition of $\gamma$-U10Mo $(\gamma)$ into $\alpha-U(\alpha)$ and $\gamma^{\prime}-U_{2}$ Mo $\left(\gamma^{\prime}\right)$ was examined in detail by electron diffraction and quantitative image analysis, because the HIP process is carried out near the eutectoid temperature [14]. 


\section{Background}

Pure U exhibits two allotropic transformations, and thus three different crystal structures. Orthorhombic $\alpha$-, tetragonal $\beta$ - and body-centered cubic (BCC) $\gamma$-phases are stable up to $667^{\circ} \mathrm{C}$, between $667^{\circ}$ and $771^{\circ} \mathrm{C}$, and above $771^{\circ} \mathrm{C}$, respectively [14-17]. The $\alpha$-U has undesirable characteristics as a nuclear fuel such as low hardness, rapid oxidation, low corrosion resistance and anisotropic irradiation behavior [18-21]. A single crystal of $\alpha$ shortens in a-axis and extends in b-axis, and there is no significant change in c-axis during irradiation under $500^{\circ} \mathrm{C}[16,22]$, leading to dimensional instability $[23,24]$.

In contrast, the $\gamma$-phase exhibits favorable properties as a nuclear fuel. The bcc $\gamma$ displays good dimensional stability because of isotropic expansion during irradiation [24]. The $\gamma$-phase also has a higher corrosion resistance to water, both liquid and vapor [25]. In order to retain the metastable $\gamma$-phase below $560^{\circ} \mathrm{C}$, rapid cooling or alloying additions has been employed [26, 27]. It is difficult for pure $U$ to exist as $\gamma$-phase even after quenching, because $\alpha$-phase is thermodynamically favorable at low temperature [24,26,27]. Thus, alloying U with Mo or $\mathrm{Zr}$ or $\mathrm{Nb}$ has been adopted to stabilized the $\gamma$-phase and produce good irradiation behavior [28-30]. Table 1 shows the characteristics of potential alloying elements in $\mathrm{U}$. Mo, $\mathrm{Zr}$ and $\mathrm{Nb}$ have been considered because of appropriate characteristics such as low neutron absorption, high melting point, high thermal conductivity and good corrosion resistance among all elements. U-Mo has been selected for higher uranium density, stabilization of $\gamma$-phase, favorable properties listed in Table 1, despite the higher thermal neutron absorption and thermal conductivity, and excellent irradiation behavior $[5,6,24,29,31]$.

The $\gamma$ decomposition is affected by the Mo concentration in the alloy. The timetemperature-transformation (T-T-T) diagram presented in Figure 1 [27] demonstrates that the 
decomposition is hindered by the Mo addition. With the Mo content $8 \mathrm{wt} . \%$ or above, the $\gamma$ phase is stabilized even from slow cooling with acceptable uranium density for good irradiation behavior [32].

Despite the sluggish kinetics, according to the equilibrium phase diagram, the hightemperature $\gamma$-phase undergoes a eutectoid decomposition upon cooling into low-temperature orthorhombic $\alpha$ - and tetragonal $\gamma^{\prime}$-phases as shown in Figure 2 [14, 34-36]. The equilibrium temperature of decomposition is relevant to the high temperature employed during co-rolling and HIP for the monolithic fuel system. Table 2 lists selected and relevant properties of the $\gamma-, \alpha$ - and $\gamma^{\prime}$-phases. Generally, the microstructure related to the decomposition was observed first at $\gamma$ phase grain boundaries $[28,37]$.

Figure 3 presents the T-T-T diagram that illustrates the time-dependent phase decomposition of the $\gamma$-phase in U10Mo alloy. The T-T-T diagrams of Repas et al. [26] and Peterson $e t$ al. [27] were constructed based on hardness, dilatometry, XRD and metallographic analyses. Saller et al. [37] also reported measurements of the electrical resistivity and hardness for U-21 at.\% Mo alloy, indicating a structural transformation from BCC to an ordered bodycentered tetragonal through isothermal transformation study at $500^{\circ} \mathrm{C}$. The transformation began approximately at 27 hours and completed around 170 hours. It should be noted that a reverse decomposition, i.e., $\alpha$ and $\gamma^{\prime}$ into $\gamma$ was observed during irradiation testing $[38,39]$.

Figure 4 shows a typical backscatter electron (BSE) micrograph of the HIP fuel plate investigated in this study. The U10Mo fuel alloy was cladded in AA6061 with a Zr diffusion barrier in-between. Microstructure of the U10Mo alloy in HIP fuel plates was characterized by scanning electron microscopy (SEM), transmission electron microscopy (TEM), and a variety of analytical techniques including X-ray energy dispersive spectroscopy (XEDS). Quantitative 
image analyses were carried out to estimate volume fraction of decomposed regions based on BSE micrographs.

\section{Experimental details}

The U10Mo alloy was fabricated by arc-melting pellets of depleted $U$ and $99.95 \%$ pure Mo which were cleaned with $30 \%$ nitric-acid to remove oxidation at the surface. The melting process was carried out in a vacuum of $1.3 \times 10^{-3} \mathrm{~Pa}\left(10^{-5}\right.$ Torr $)$ containing less than $50 \mathrm{ppm}$ oxygen, and the U10Mo alloy was turned and re-melted three times in graphite crucible to ensure the homogeneity. The cast U10Mo alloy had an approximate dimension of $88.8 \times 48.9 \times 3.2 \mathrm{~mm}$ and a carbon content of approximately $700 \mathrm{ppm}$. The ingot was laminated in a carbon steel can using a pure $\mathrm{Zr}(99.9 \%$ pure) foil with a starting thickness of $250 \mu \mathrm{m}$ on each surface. $\mathrm{A} \sim 30 \%$ nitric acid solution was used to etch the reactor-grade $\mathrm{Zr}$ prior to lamination. The Zr-laminated U10Mo coupon, pre-heated at $650^{\circ} \mathrm{C}$ for 30 minutes in a furnace, was co-rolled 15 times to a thickness of approximately $0.46 \mathrm{~mm}$. Subsequently, a post-rolling heat treatment was performed at $650^{\circ} \mathrm{C}$ for 45 minutes. The hot-rolled and annealed foil was removed from the can, and coldrolled to a final thickness of $0.33 \mathrm{~mm}$. The final dimension of as-rolled foil was approximately $746 \times 65 \times 0.33 \mathrm{~mm}$. The foil was exposed for approximately 130 minutes at $650^{\circ} \mathrm{C}$. The final thickness of the $\mathrm{Zr}$ diffusion barriers on each surface was approximated at $25 \mu \mathrm{m}$. Each small UMo foil sectioned from the as-rolled parent foil was used in this study. In general, each small foil sample exhibited the same microstructure in the co-rolled $\mathrm{U} 10 \mathrm{Mo} / \mathrm{Zr}$ laminate previously observed by Park et al. [9]. "AR" in this study is defined as the as-co-rolled/sectioned sample prior to the HIP process.

The polished AR sample (each U10Mo/Zr mini foil) was cleaned using a mixture of nitric and hydrofluoric acid $\left(2.5 \% \mathrm{HF}, 35 \% \mathrm{HNO}_{3}\right.$ and $\left.62.5 \% \mathrm{H}_{2} \mathrm{O}\right)$, and any residual oxide scale of 
AA6061 cladding was removed by etching using a $1.85 \mathrm{M} \mathrm{NaOH}$ and then a $30 \%$ nitric acid solution. After cleaning, the AR samples were rinsed with ethanol and stacked with AA6061 (in wt. \% nominal composition of $0.6 \mathrm{Si}-0.35 \mathrm{Fe}-0.28 \mathrm{Cu}-0.08 \mathrm{Mn}-1.0 \mathrm{Mg}-0.20 \mathrm{Cr}-0.13 \mathrm{Zn}-0.08 \mathrm{Ti}-\mathrm{Al}$ balance) cladding pieces. The U10Mo/Zr minifoil was then HIP'ed with the AA6061 at various temperatures $\left(520,540,560\right.$ and $\left.580^{\circ} \mathrm{C}\right)$ and durations $(45,60,90180$ and 345 minutes). The U10Mo/Zr/AA6061 assemblies were placed into stainless steel HIP cans with tool-steel strongbacks that were welded with corners open for degassing in an argon atmosphere glove box. The assemblies were subsequently leak-checked and vacuum degassed at $315^{\circ} \mathrm{C}$ for $3 \mathrm{~h}$. After loading into a laboratory-size HIP, the HIP cans were heated with heat-up and cool-down rates (H/C rate) of 35,70 and $280^{\circ} \mathrm{C} / \mathrm{h}$ to the target temperature. The isostatic pressure of $103 \mathrm{MPa}(15$ ksi) for HIP process was applied in an argon environment. The samples characterized as functions of HIP parameters in this study are listed in Table 3.

After fabrication, the fuel plates were cross-sectioned and mounted in epoxy. The mounted fuel plates were polished using silicon carbide papers (240, 600, 800 and 1200 grits) with an ethanol lubricant. Final polishing was carried out utilizing diamond pastes ( 3 and $1 \mu \mathrm{m})$ with an oil lubricant in an Ar glove box to prevent oxidation and contamination. Microstructural features in U10Mo solid solution were examined utilizing a Zeiss ULTRA-55 field-emission SEM with XEDS capabilities. High-contrast in backscatter electron micrographs were utilized to distinguish the different phases and quantitative analyses. Transmission electron microscopy (FEI/Tecnai ${ }^{\mathrm{TM}} \mathrm{F} 30$ ) equipped with Fischione ${ }^{\mathrm{TM}}$ high angle annular dark-field (HAADF) and XEDS were used to examine the detailed microstructures and identify the phase constituents via selected area electron diffraction (SAED) and high resolution TEM (HRTEM). The TEM samples were prepared by focused ion beam and an in-situ lift-out process was utilized for 
sample extraction (FIB-INLO; FEITM TEM200) using site-specific capability. Typical phase constituents and microstructural developments due to interdiffusion and reaction at the $\mathrm{U} 10 \mathrm{Mo} / \mathrm{Zr}$ and $\mathrm{Zr} / \mathrm{AA} 6061$ interfaces in these samples were reported previously [8, 9]. This paper reports, in detail, the phase transformation of $\gamma$-phase in the U10Mo fuel alloy as functions of HIP temperature, holding time and ramping/cooling (H/C) rate as listed in Table 3.

\section{Result and discussion}

The AR sample before HIP process exhibited a small amount of cellular structure which consists of $\alpha$-, $\gamma$ - and $\gamma^{\prime}$-phases as shown in Figure 5. The cellular structure is assumed as the initial feature associated with onset of $\gamma^{\prime}$-formation (i.e., start of the $\alpha+\gamma+\gamma^{\prime}$ phase region in Figure 3) prior to development of lamellar structure, and is also assumed to nucleate at heterogeneous sites, such as grain boundaries. Only the cellular structure without any lamellar features were observed in the AR sample. The cellular structure is also characterized by the Mo depleted regions surrounding the Mo-rich $\gamma^{\prime}$ nuclei as shown by the inset in Figure 5. Based on these observations, AR sample is assumed to exhibit features characteristic of an U10Mo alloy corresponding to a time coordinate of 25 hours in the U10Mo T-T-T diagram as labeled in Figure 3. In other words, subsequent HIP and the corresponding characterization results assume that the starting coordinates for U10Mo alloy fuel in T-T-T diagram is at 25 hours as labeled in Figure 3.

Figure 6 shows microstructure of U10Mo fuel alloy HIP'ed at $560^{\circ} \mathrm{C}$ for 90 minutes with a $\mathrm{H} / \mathrm{C}$ rate variation of 280,70 and $35^{\circ} \mathrm{C} /$ hour. The micrograph in Figure 6(a) from the U10Mo alloy with the higher $\mathrm{H} / \mathrm{C}$ rate of $280^{\circ} \mathrm{C}$ /hour shows cellular regions along grain boundaries of U10Mo alloy. Cellular structure is better defined than the AR sample, and some of the cellular reaction was observed within the grains of the U10Mo solid solution. For U10Mo alloy HIP'ed 
with $\mathrm{H} / \mathrm{C}$ rate of $70^{\circ} \mathrm{C} /$ hour, a clear development of lamellar structure was observed in addition to the cellular structure as shown in Figure 6(b). The lamellar structure is assumed to begin from the cellular precipitates along the grain boundaries, and grow into the grain of $\gamma$-(U10Mo). The largest volume fraction of lamellar structure region was observed in the sample with $35^{\circ} \mathrm{C} /$ hour $\mathrm{H} / \mathrm{C}$ rate. The lamellar structure of $\alpha$ and $\gamma^{\prime}$ is presented in detail with a higher magnification BSE micrograph in Figure 7. Figure 8 shows that the volume fraction estimated for the lamellar structure region resulting from decomposition of $\gamma$ increases as the $\mathrm{H} / \mathrm{C}$ rate decrease. This observation corresponds to the fact that slow $\mathrm{H} / \mathrm{C}$ rate exposes the U10Mo alloy in the threephase $\left(\alpha+\gamma+\gamma^{\prime}\right)$ region the longest as illustrated on the T-T-T diagram in Figure 9.

A selected region highlighted by black rectangle in Figure 6 (c) was prepared by FIBINLO for TEM analyses presented in Figures 10 and 11. The SAED patterns presented in Figure 11 were collected from circled regions in Figure 10(a). The HAADF and bright-field images shown in Figure 10 along with SAED patterns presented in Figure 11 were employed to identify the decomposition of bcc- $\gamma$ into alternating orthorhombic- $\alpha$ and tetragonal- $\gamma$ ' lamellar structure. These phases were identified by analyzing the SAED patterns, and the crystallographic characteristics of each phase corresponded well to those reported in Table 2. Variation in Mo composition in g-phase with $\sim 10 \mathrm{wt} . \%$ Mo, Mo-depleted $\alpha$, Mo-enriched $\gamma^{\prime}$ was also confirmed by extensive analyses by XEDS equipped on TEM. Other regions consisted of $\gamma$ and $\alpha$, without $\gamma^{\prime}$. Therefore the presence of transition region from $\alpha+\gamma$ to $\alpha+\gamma+\gamma$ ' in the T-T-T diagram appears to be consistent with the current TEM analyses.

Figure 12 shows microstructural variation in U10Mo fuel alloy as a function of HIP temperature. The time at HIP temperature and $\mathrm{H} / \mathrm{C}$ rate remained constant for 90 minutes and $280^{\circ} \mathrm{C} /$ hour, respectively, for these samples. In general, the volume fractions of cellular and 
lamellar structure regions decreased with an increase in HIP temperature as presented in Figure 13. The HIP temperature variation examined in this study is close to the transition that separates $\gamma$ and $\alpha+\gamma$ (and $\alpha+\gamma$ and $\gamma$ ) on the upper-left-corner of the T-T-T diagram as presented in Figure 14. Repas et al. [26] postulated a transition between $\alpha+\gamma^{\prime}$ and $\alpha+\gamma$ at $573^{\circ} \mathrm{C}$ (lower critical temperature), and between $\alpha+\gamma^{\prime}$ and $\gamma$ at $580^{\circ} \mathrm{C}$ (upper critical temperature) in the T-T-T diagram. However, these temperatures have been subject to some scrutiny by other investigations [14, 29, 37, 38, 40, 41]. Table 4 summarizes the critical transition temperatures reported in literature $[14,26,39]$ for the $\mathrm{U}-10 \mathrm{wt}$ \% Mo alloy. In this study, the samples HIP'ed at 520 and $540^{\circ} \mathrm{C}$ show the lamellar structure of $\alpha$ and $\gamma^{\prime}$ within the $\gamma$ matrix, while only cellular structure was observed when the samples were HIP'ed at $560^{\circ} \mathrm{C}$ and above. This demonstrates the transition of $\alpha$ and $\gamma^{\prime}$ into $\alpha$ and $\gamma$ starts above $540^{\circ} \mathrm{C}$ and below $560^{\circ} \mathrm{C}$.

Effects of HIP holding time was examined with U10Mo alloys HIP'ed at $560^{\circ} \mathrm{C}$ with $\mathrm{H} / \mathrm{C}$ rate of $280^{\circ} \mathrm{C} / \mathrm{h}$ as presented in Figure 15 . There was no significant change in the amount of decomposed region because, upon heating, a transformation from $\alpha+\gamma^{\prime}$ (or $\left.\alpha+\gamma+\gamma^{\prime}\right)$ into $\alpha+\gamma$ in the temperature range of 555 to $580^{\circ} \mathrm{C}$ is expected as shown in Figure 16. Given the HIP temperature of $560^{\circ} \mathrm{C}$, the volume fraction of decomposed region showed no significant trend with HIP holding time, up to 345 minutes, as shown in Figure 17. However such an observation may change when HIP temperature is selected at $540^{\circ} \mathrm{C}$ or below (e.g., $555^{\circ} \mathrm{C}$ according to Okamoto) according to the T-T-T diagram. Therefore, in order to minimize the decomposition of the $\gamma$-phase into $\alpha$ - and $\gamma^{\prime}$-phases in the U10Mo fuel, HIP utilizing at least $560^{\circ} \mathrm{C}$ and the highest $\mathrm{H} / \mathrm{C}$ rate would be recommended. HIP at $580^{\circ} \mathrm{C}$ may allow longer duration without concern for any decomposition. 
A related consideration for higher HIP temperature is the interdiffusion and reaction among U10Mo fuel alloy, Zr diffusion barrier, and AA6061 cladding alloy. In our previous study, HIP did not cause any observable growth of the interaction layer at the U10Mo/Zr interface within the temperatures and holding time range examined [9]. Development of the interaction layer containing $\alpha-\mathrm{U}, \mathrm{UZr}_{2}$, and $\mathrm{Mo}_{2} \mathrm{Zr}$ at the $\mathrm{U} 10 \mathrm{Mo} / \mathrm{Zr}$ interface primarily occurred during the co-rolling process $\left(650^{\circ} \mathrm{C}\right)$ prior to HIP. However, the intermetallic $(\mathrm{Al}, \mathrm{Si})_{3} \mathrm{Zr}$ at the $\mathrm{AA} 6061 / \mathrm{Zr}$ interface was observed to grow with the HIP duration, and the growth followed the Arrhenius relation with an activation energy of $457.54 \pm 27.60 \mathrm{~kJ} / \mathrm{mole}$. Figure 18 illustrates the growth kinetics of $(\mathrm{Al}, \mathrm{Si})_{3} \mathrm{Zr}$ at the AA6061/Zr interface [9]. Therefore the HIP process for the monolithic fuel system should employ higher temperature (e.g., $560^{\circ}$ and $580^{\circ} \mathrm{C}$ ) to (1) ensure the highest quality of adhesion at the U10Mo/Zr and AA6061/Zr interfaces $[9,10]$, and (2) minimize the $\gamma$-phase decomposition, (3) however, without excessive growth of $(\mathrm{Al}, \mathrm{Si})_{3} \mathrm{Zr}$ layer at the AA6061/Zr.

\section{Conclusion}

$\mathrm{U}-10$ wt.\% Mo alloy for the monolithic fuel plates encased in AA6061 cladding with Zr barrier was characterized as functions of HIP parameters with an emphasis on decomposition of $\gamma$-phase into $\alpha$ - and $\gamma^{\prime}$-phases. From TEM SAED, the constituent phases of the U10Mo alloy consisted of $\gamma$ cI $2 \operatorname{Im} 3 \mathrm{~m}(3.474 \times 3.474 \times 3.474 \AA), \alpha$ oC4 Cmcm $(2.854 \times 5.869 \times 4.955 \AA)$ and $\gamma^{\prime}$ tI6 I4/mmm (3.427×3.427×9.834 $\AA$ ). The $\alpha$ - and $\gamma^{\prime}$-phases formed by decomposition of the $\gamma$ phase because the HIP process was carried out near the eutectoid temperature with varying HIP parameters including ramping/cooling rate, temperature, and holding time. Initially, a cellular structure of $\alpha$ and $\gamma^{\prime}$ from the decomposition of $\gamma$ developed discontinuously on grain boundaries, 
and evolved into lamellar structures of alternating $\alpha$ and $\gamma^{\prime}$. Volume fraction associated with decomposition (e.g., cellular and lamellar structure) decreased with (1) an increase in ramping/cooling rate, (2) an increase in HIP temperature due to $\gamma$-phase stabilization at higher temperature. There was no significant development of decomposed lamellar structure when the HIP was carried out at $560^{\circ} \mathrm{C}$ for up to 345 minutes.

\section{Acknowledgements}

This work was supported by the U.S. Department of Energy, Office of Nuclear Materials Threat Reduction (NA-212), National Nuclear Security Administration, under DOE-NE Idaho Operations Office Contract DE-AC07-05ID14517. Accordingly, the U.S. Government retains a non-exclusive, royalty-free license to publish or reproduce the published form of this contribution, or allow others to do so, for U.S. Government purposes.

\section{References}

[1] A. Travelli, "The Effect of Reduced Enrichment on the Fuel Cycle for Research Reactors," The International Topical Meeting on Nuclear Fuel Cycles and Waste Disposal, Brussels, Belgium, 1982, IAEA-CONF-820420-12.

[2] J.L. Snelgrove, G.L. Hofman, M.K. Meyer, C.L. Trybus, T.C. Wiencek, Nuclear Engineering and Design, 178 (1997) 119-126.

[3] D.D. Keiser, Jr., S.L. Hayes, M.K. Meyer, C.R. Clark, Journal of Metals, 55 (2003) 55-58.

[4] S. Van Den Berghe, A. Leenaers, E. Koonen, L. Sannen, Advances in Science and Technology, 73 (2010) 78-90. 
[5] A.B. Robinson, G.S. Chang, D.D. Keiser Jr, D.M. Wachs, D.L. Porter, "Irradiation Performance of U-Mo Alloy Based "Monolithic" Plate-Type Fuel - Design and Selection," Idaho National Laboratory, Idaho Falls, Idaho, 2009, INL/EXT-09-16807.

[6] Y.S. Kim, “Uranium Intermetallic Fuels (U-Al, U-Si, U-Mo),” in: Konings R.J.M., (ed.) Comprehensive Nuclear Materials, volume 3, pp. 391-422, Elsevier, 2012.

[7] G.L. Hofman, M.K. Meyer, "Progress in Irradiation Performance of Experimental Uranium-Molybdenum Dispersion Fuel,” The 24th Interational Meeting on Reduced Enrichment for Research and Test Reactors, San Carlos de Bariloche, Argentina, 2002.

[8] Y. Park, N. Eriksson, D.D. Keiser Jr, J.F. Jue, B. Rabin, G. Moore, Y.H. Sohn, Materials Characterization, 103 (2015) 50-57.

[9] Y. Park, J. Yoo, K. Huang, D.D. Keiser Jr, J.F. Jue, B. Rabin, G. Moore, Y.H. Sohn, Journal of Nuclear Materials, 447 (2014) 215-224.

[10] E. Perez, B. Yao, D.D. Keiser Jr, Y.H. Sohn, Journal of Nuclear Materials, 402 (2010) 814.

[11] M.K. Meyer, G.A. Moore, J.F. Jue, D.D. Keiser Jr, I.Y. Glagolenko, D.M. Wachs, P.E. Murray, A.B. Robinson, F.J. Rice, H. Ozaltun, S.J. Miller, M.A. Okuniewski, B.H. Rabin, H.W. Glunz, N.J. Lybeck, "Investigation of the Cause of Low Blister Threshold Temperatures in the RERTR-12 and AFIP-4 Experiments," Idaho National Laboratory, 2012, INL/EXT-12-26500.

[12] J.-F. Jue, D.D. Keiser Jr, C.R. Breckenridge, G.A. Moore, M.K. Meyer, Journal of Nuclear Materials, 448 (2014) 250-258.

[13] G.A. Moore, F.J. Rice, N.E. Woolstenhulme, W.D. Swank, D. Haggard, J. Jue, B.H. Park, S.E. Steffler, N.P. Hallinan, M.D. Chapple, D.E. Burkes, "Monolithic Fuel Fabrication 
Process Development at the Idaho National Laboratory,” The 30th International Meeting on Reduced Enrichment for Research and Test Reactors, Washington, DC, USA, 2008.

[14] H. Okamoto, Journal of Phase Equilibria and Diffusion, 33 (2012) 497-497.

[15] H.L. Yakel, "A Review of X-ray Diffraction Studies in Uranium Alloys,” The Physical Metallurgy of Uranium Alloys Conference, 1974, ORNL-CONF-740205-9.

[16] C.V. Sundaram, S.L. Mannan, Sadhana, 14 (1989) 21-57.

[17] M. Lehmann, Journal of Nuclear Materials, 2 (1960) 261-268.

[18] R.L. Miller, G.A. Reimann, "Thermodynamics of Gas-Metal-Slag Equilibria for Applications in In Situ and Ex Situ Vitrification Melts,” Idaho National Engineering Laboratory, 1993, EGG-MS-10613.

[19] M.M. Baker, L.N. Less, S. Orman, Transactions of the Faraday Society, 62 (1966) 25252530.

[20] J.M. Macki, R.L. Kochen, "Corrosion Behavior of Uranium-Base U-NB, U-NB-Zr, And UMo Alloys in Hydrochloric Acid and Ocean Water," US Atomic Energy Commission, 1971, DOI: $10.2172 / 4051383$.

[21] V.F. Peretrukhin, A.G. Maslennikov, A.Y. Tsivadze, C.H. Delegard, A.B. Yusov, V.P. Shilov, A.A. Bessonov, K.E. German, A.M. Fedoseev, L.P. Kazanskii, N.Y. Budanova, A.V. Kareta, A.V. Gogolev, K.N. Gedgovd, G.S. Bulatov, Protection of Metals, 44 (2008) 211-232.

[22] W.R. McDonell, G.R. Caskey, C.L. Angerman, "High-Performance Uranium-Metal Fuels for Savannah River Reactors,” Westinghouse Savannah River Company 1975, WSRC-MS2000-00061. 
[23] G. Beghi, "Gamma Phase Uranium-Molybdenum Fuel Alloys," European Atomic Energy Community - Euratom, 1968, EUR 4053e.

[24] M.K. Meyer, J. Gan, J.F. Jue, D.D. Keiser Jr, E. Perez, A. Robinson, D.M. Wachs, N. Woolstenhulme, G.L. Hofman, Y.S. Kim, Nuclear Engineering and Technology, 46 (2014) 169-182.

[25] International Atomic Energy Agency, "Development status of metallic, dispersion and nonoxide advanced and alternative fuels for power and research reactors," Vienna, 2003, IAEA-TECDOC-1374.

[26] P.E. Repas, R.H. Goodenow, R.F. Hehemann, Transactions of the ASM, 57 (1964) 150-163.

[27] C.A.W. Peterson, W.J. Steele, S.L. DiGiallonardo, "Isothermal Transformation Study of Some Uranium-base Alloys,” University of California Lawrence Radiation Laboratory, 1964.

[28] S. Neogy, M.T. Saify, S.K. Jha, D. Srivastava, M.M. Hussain, G.K. Dey, R.P. Singh, Journal of Nuclear Materials, 422 (2012) 77-85.

[29] G.L. Hofman, M.K. Meyer, A.E. Ray, The 21th International Meeting on Reduced Enrichment for Research and Test Reactors, Sao Paulo, Brazil, 1998.

[30] B.-S. Seong, C.-H. Lee, J.-S. Lee, H.-S. Shim, J.-H. Lee, K.H. Kim, C.K. Kim, V. Em, Journal of Nuclear Materials, 277 (2000) 274-279.

[31] K. Huang, C.C. Kammerer, D.D. Keiser, Jr., Y.H. Sohn, Journal of Phase Equilibria and Diffusion, 35 (2014) 146-156.

[32] S. Jaroszewicz, E.L. Losada, J.E. Garcés, H.O. Mosca, Journal of Nuclear Materials, 441 (2013) 119-124. 
[33] V.P. Sinha, P.V. Hegde, G.J. Prasad, G.K. Dey, H.S. Kamath, Journal of Alloys and Compounds, 506 (2010) 253-262.

[34] N.-T.H. Kim-Ngan, I. Tkach, S. Mašková, L. Havela, A. Warren, T. Scott, Advances in Natural Sciences: Nanoscience and Nanotechnology, 4 (2013) 035006.

[35] V.P. Sinha, P.V. Hegde, G.J. Prasad, G.K. Dey, H.S. Kamath, Journal of Alloys and Compounds, 491 (2010) 753-760.

[36] H.A. Saller, F.A. Rough, A.A. Bauer, "Transformation Kinetics of Uranium-Molybdenum Alloys," U.S. Atomic Energy Commission, Battelle Memorial Institute, 1955, BMI 957.

[37] R.M. Willard, A.R. Schmitt, "Irradiation Swelling, Phase Reversion, and Intergranular Cracking of U-10wt.\%Mo Fuel Alloy,” Atomics International, 1965, NAA-SR-8956.

[38] K.H. Kim, H.J. Kwon, J.M. Park, Y.S. Lee, C.K. Kim, Journal of the Korean Nuclear Society, 33 (2001) 365-374.

[39] A.L. Lotts, "Review of Information on U-Mo Alloys and U-Mo-UO2 Dispersion Fuels," Oak Ridge National laboratory, 1960, ORNL-60-6-122.

[40] P.E. Armstrong, D.T. Eash, J.E. Hockett, Journal of Nuclear Materials, 45 (1972) 211-216.

[41] S.D. Cramer, B.S. Covino, Jr., ASM Handbook Volume 13, Corrosion: Materials, ASM International, 2003.

[42] V.F. Sears, Neutron News, 3 (1992) 26-37.

[43] W. Martienssen, H. Warlimont, Springer Handbook of Condensed Matter and Materials Data, Springer Berlin Heidelberg, 2006.

[44] E.K. Halteman, Acta Crystallographica, 10 (1957) 166-169.

[45] F.A. Rough, A.A. Bauer, "Constitution of Uranium and Thorium Alloys," Battelle Memorial Institute, 1958, BMI-1300. 
[46] A.E. Dwight, Journal of Nuclear Materials, 2 (1960) 81-87.

[47] R.J. Jackson, "Structure and Transformation Kinetics of Phases in the Uranium-Rhenium Alloy System," Ph.D. Dissertation in Metallurgy, Iowa State University, Ames, Iowa, 1964, pp. 162.

[48] S.L. Robinson, Journal of Nuclear Materials, 46 (1973) 293-302.

[49] D.E. Burkes, G.S. Mickum, D.M. Wachs, “Thermophysical Properties of U-10Mo Alloy,” Idaho National Laboratory, 2010, INL/EXT-10-19373.

[50] D.E. Burkes, R. Prabhakaran, T. Hartmann, J.-F. Jue, F.J. Rice, Nuclear Engineering and Design, 240 (2010) 1332-1339.

[51] T.R.G. Kutty, S. Dash, J. Banerjee, S. Kaity, A. Kumar, C.B. Basak, Journal of Nuclear Materials, 420 (2012) 193-197. 


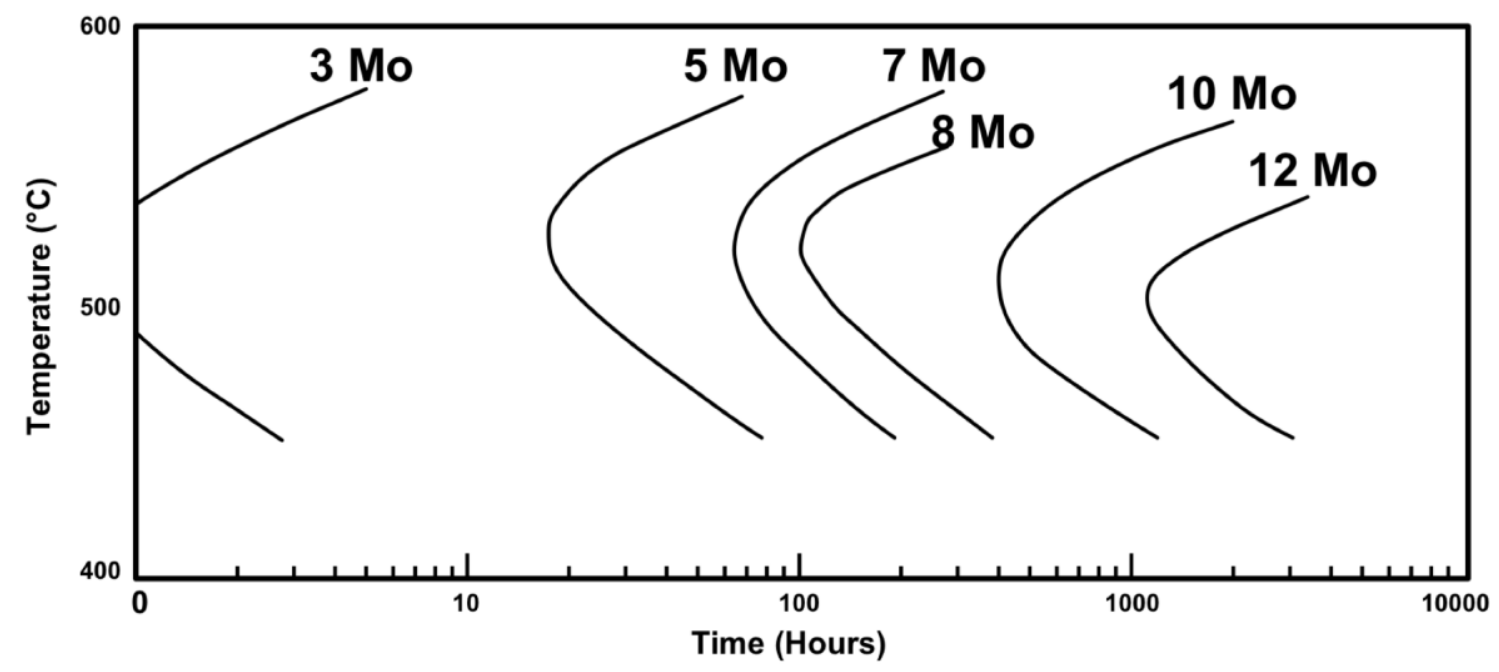


(a)

Weight Percent Uranium
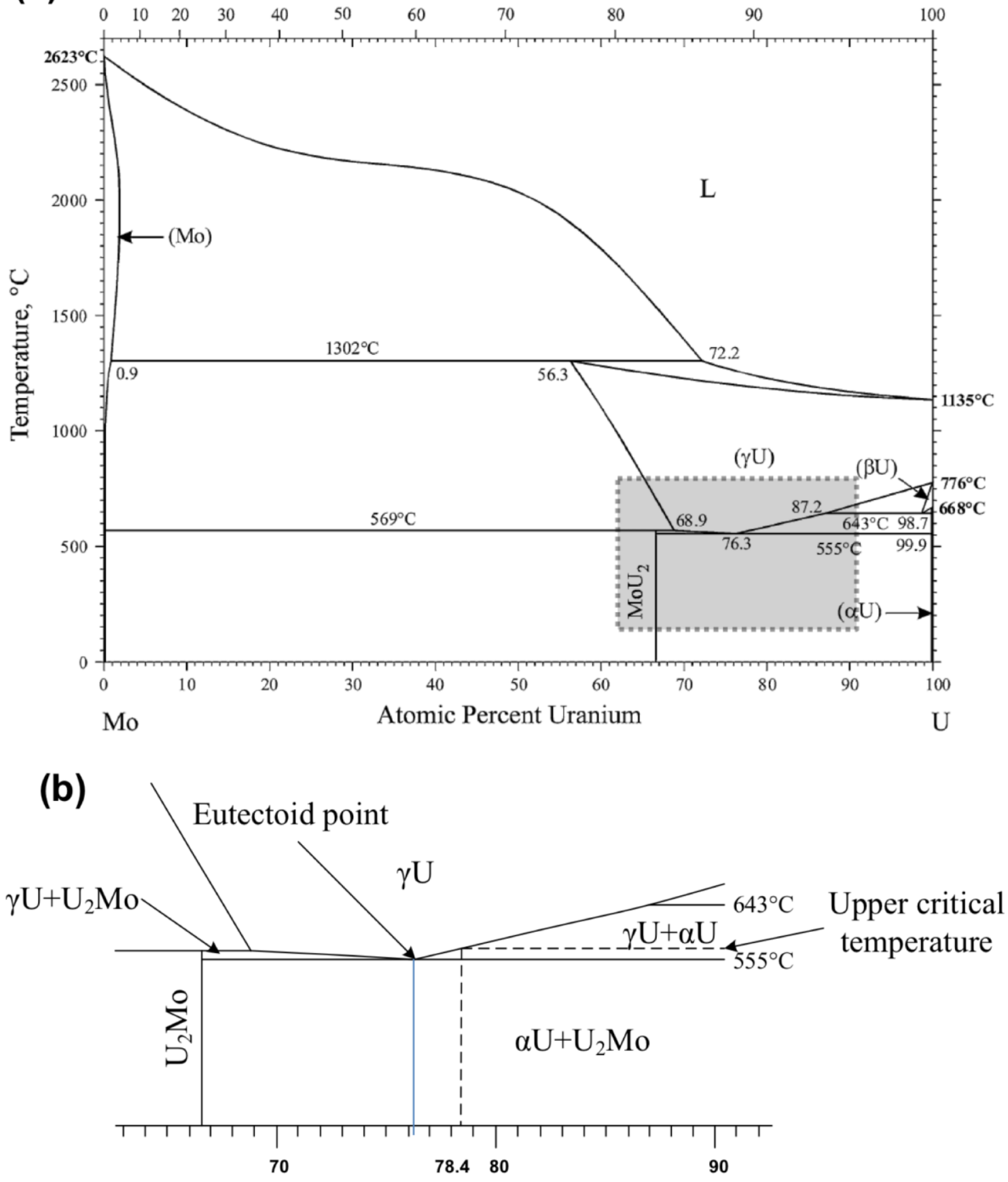

Atomic Percent Uranium 


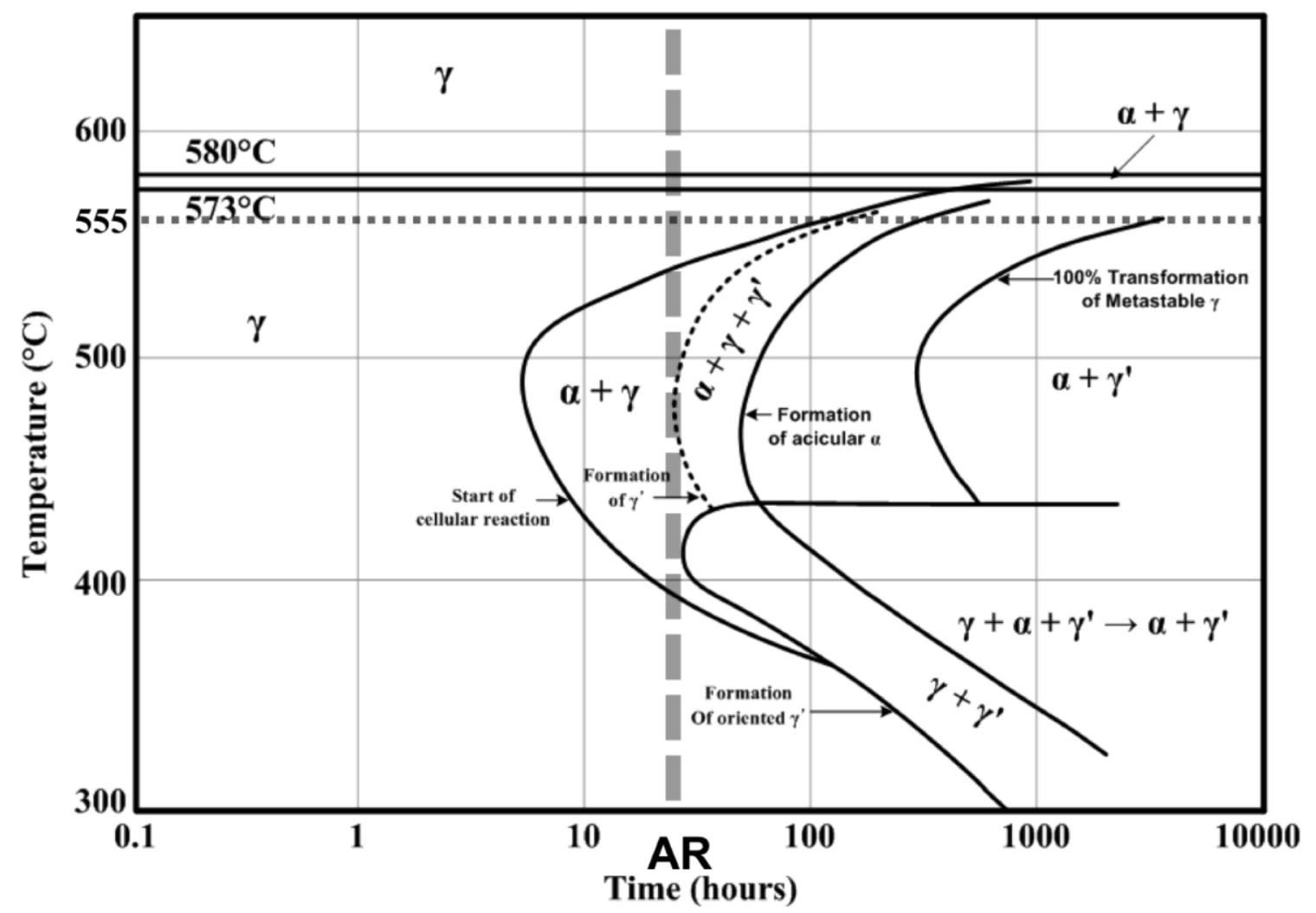




\section{AA6061}

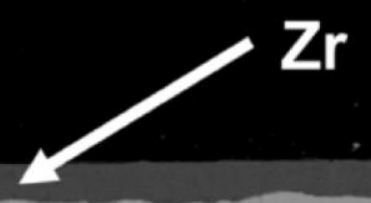

\section{U-10 wt.\% Mo}




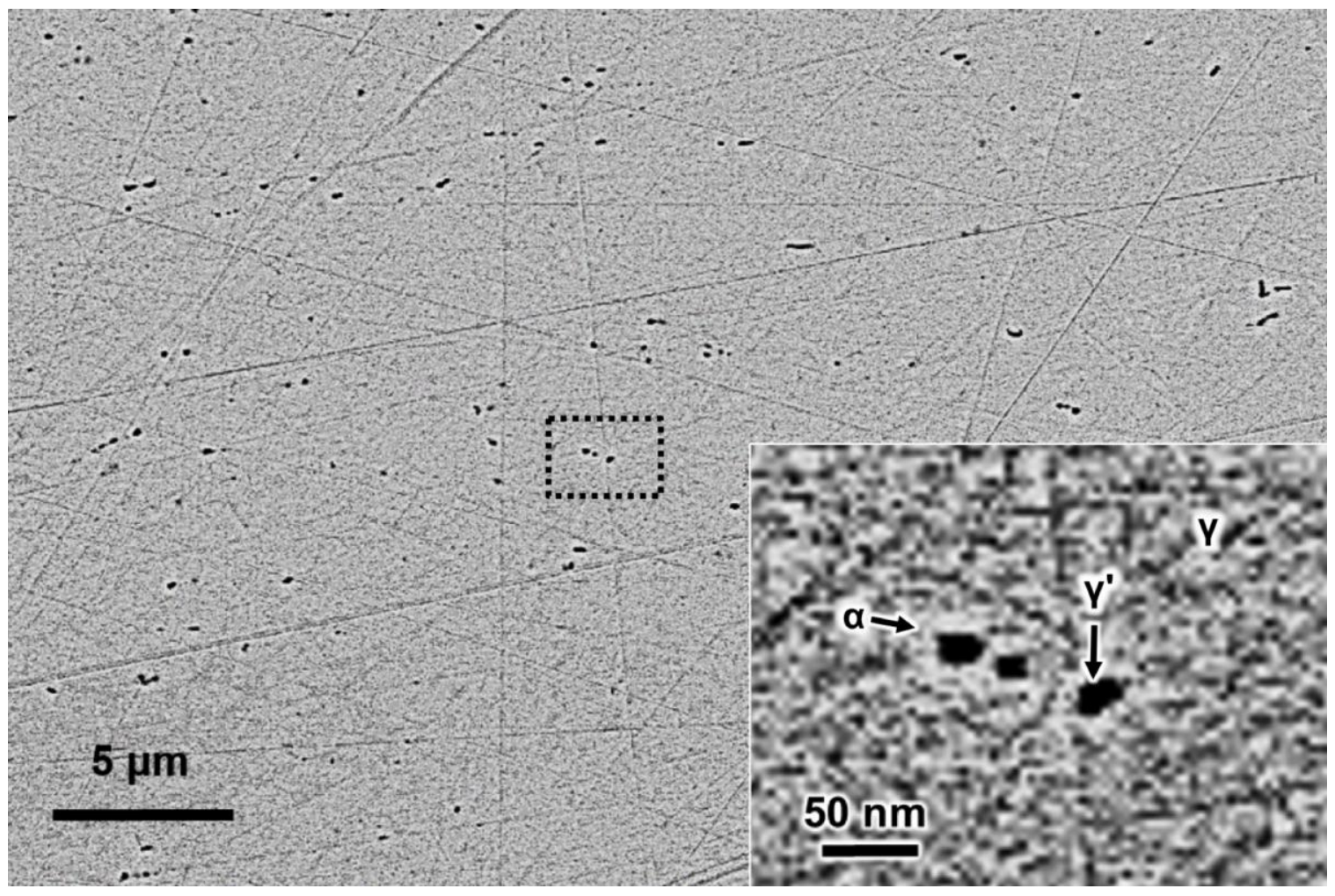



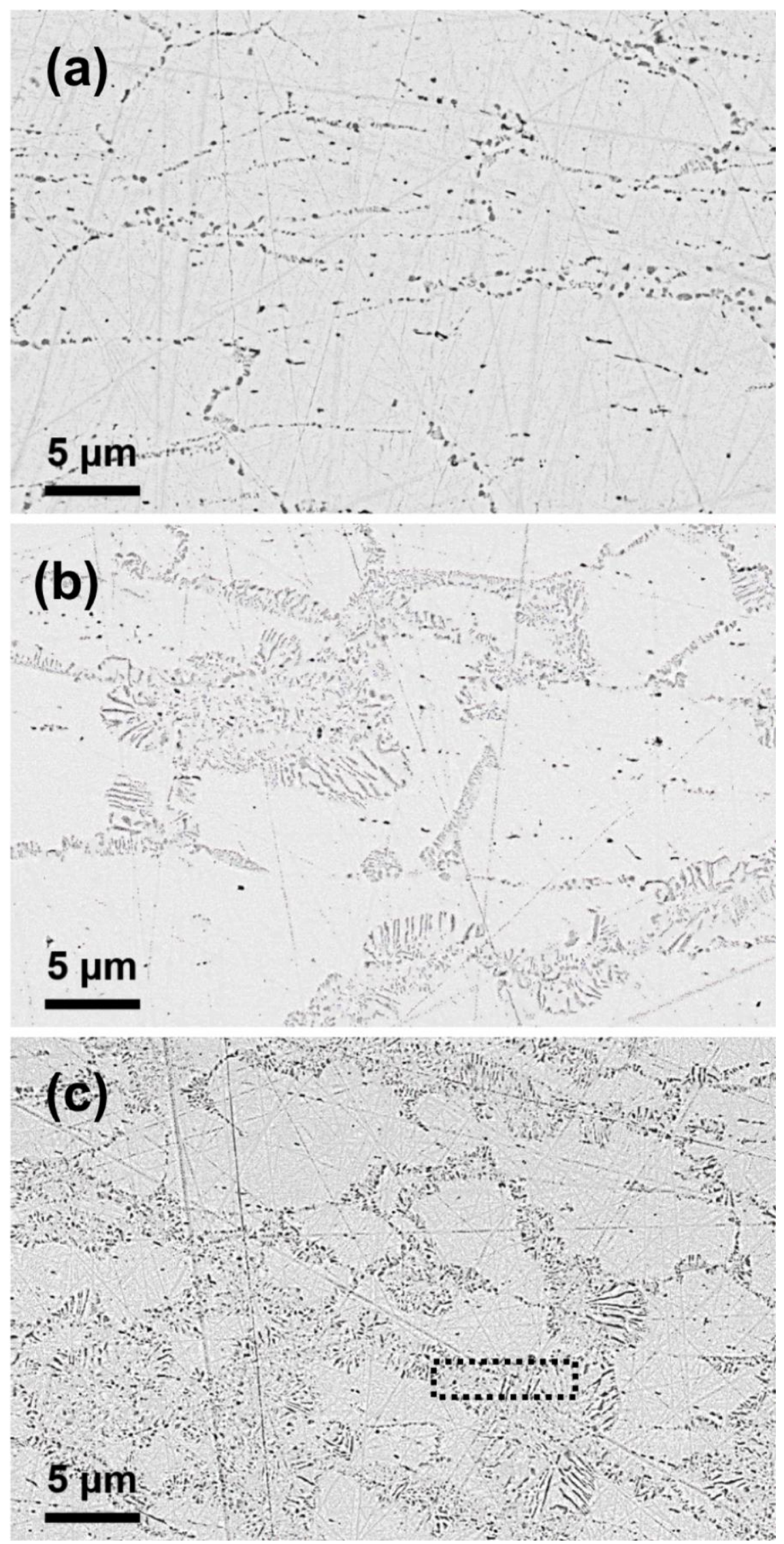


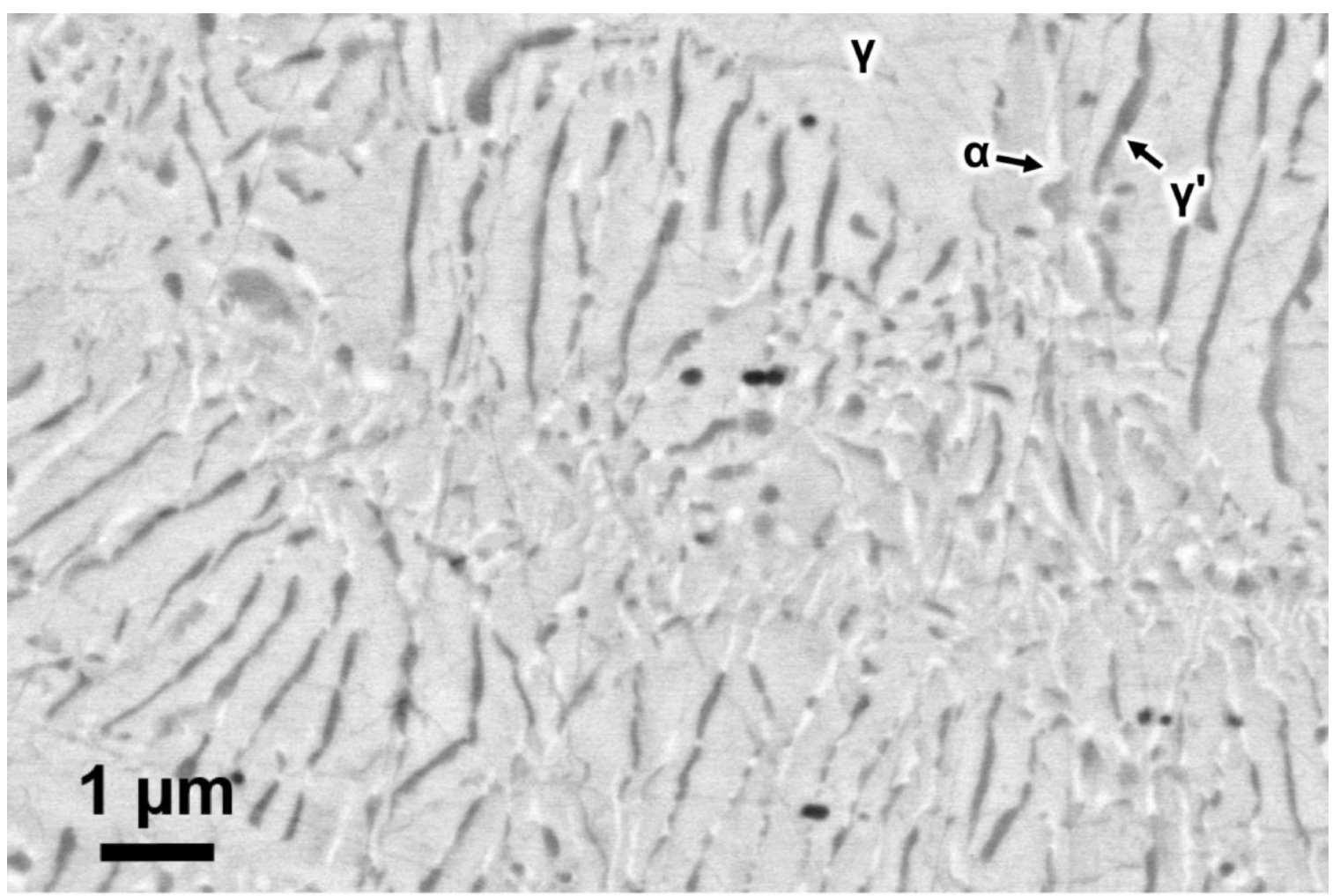




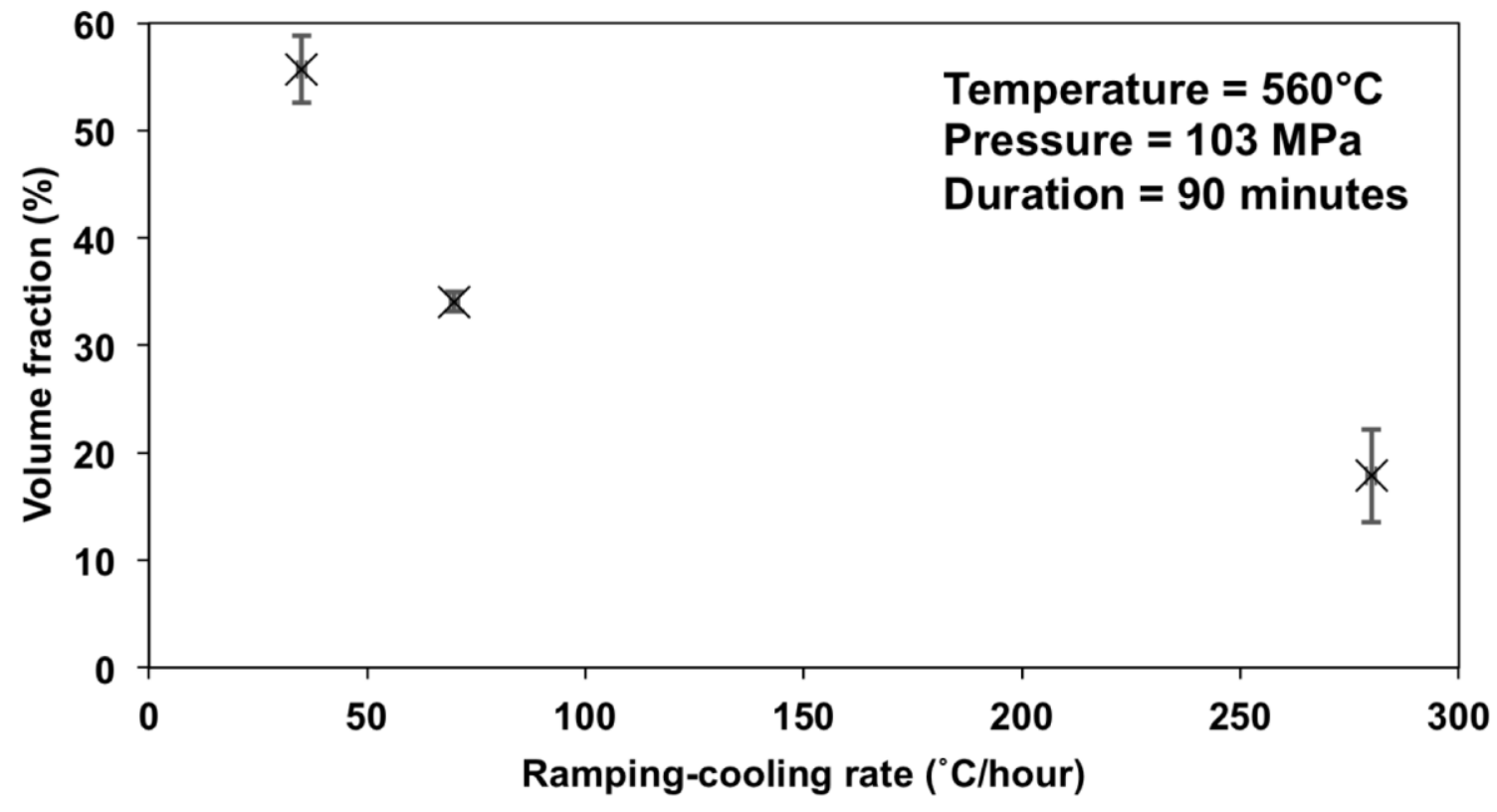




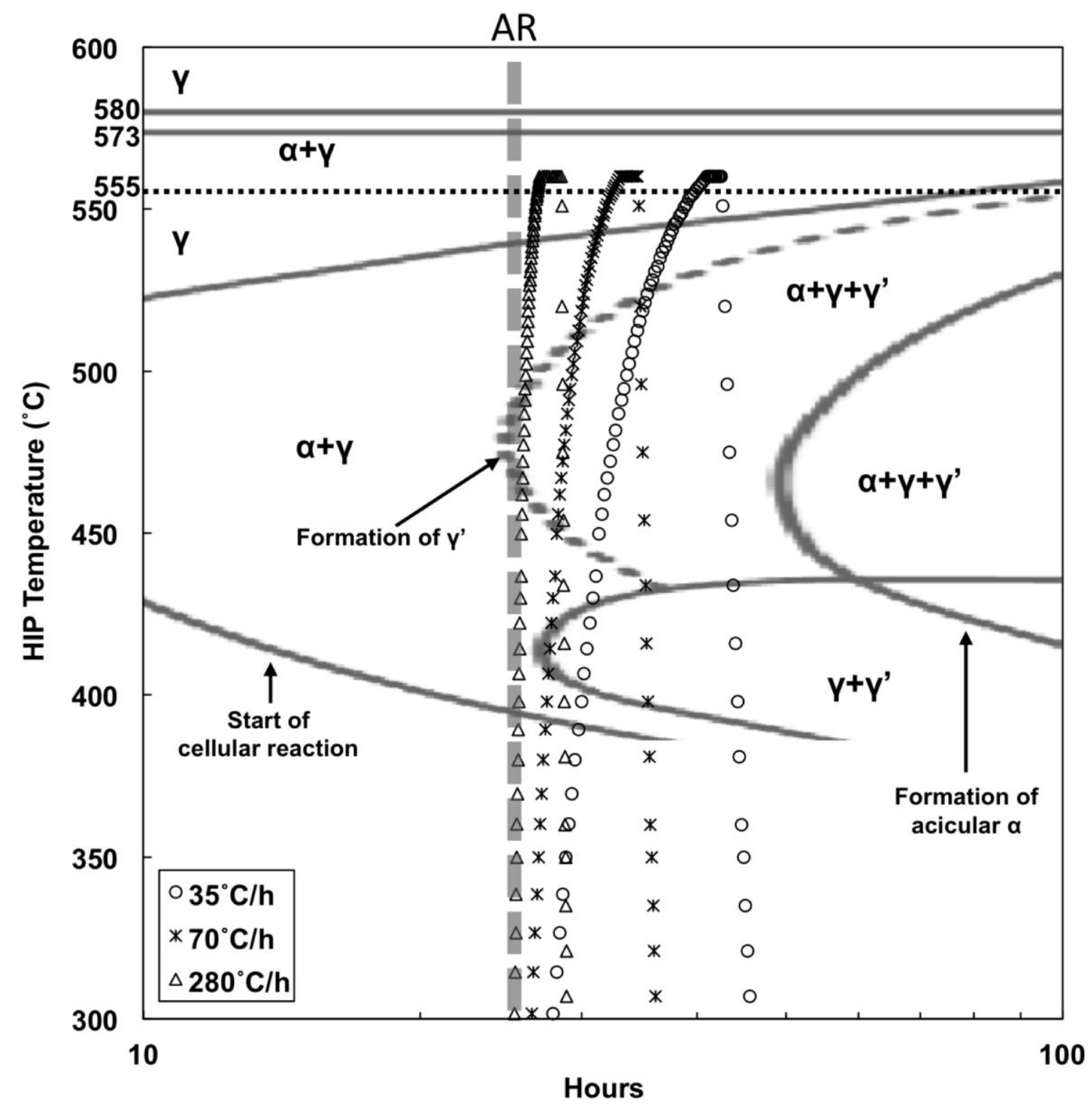



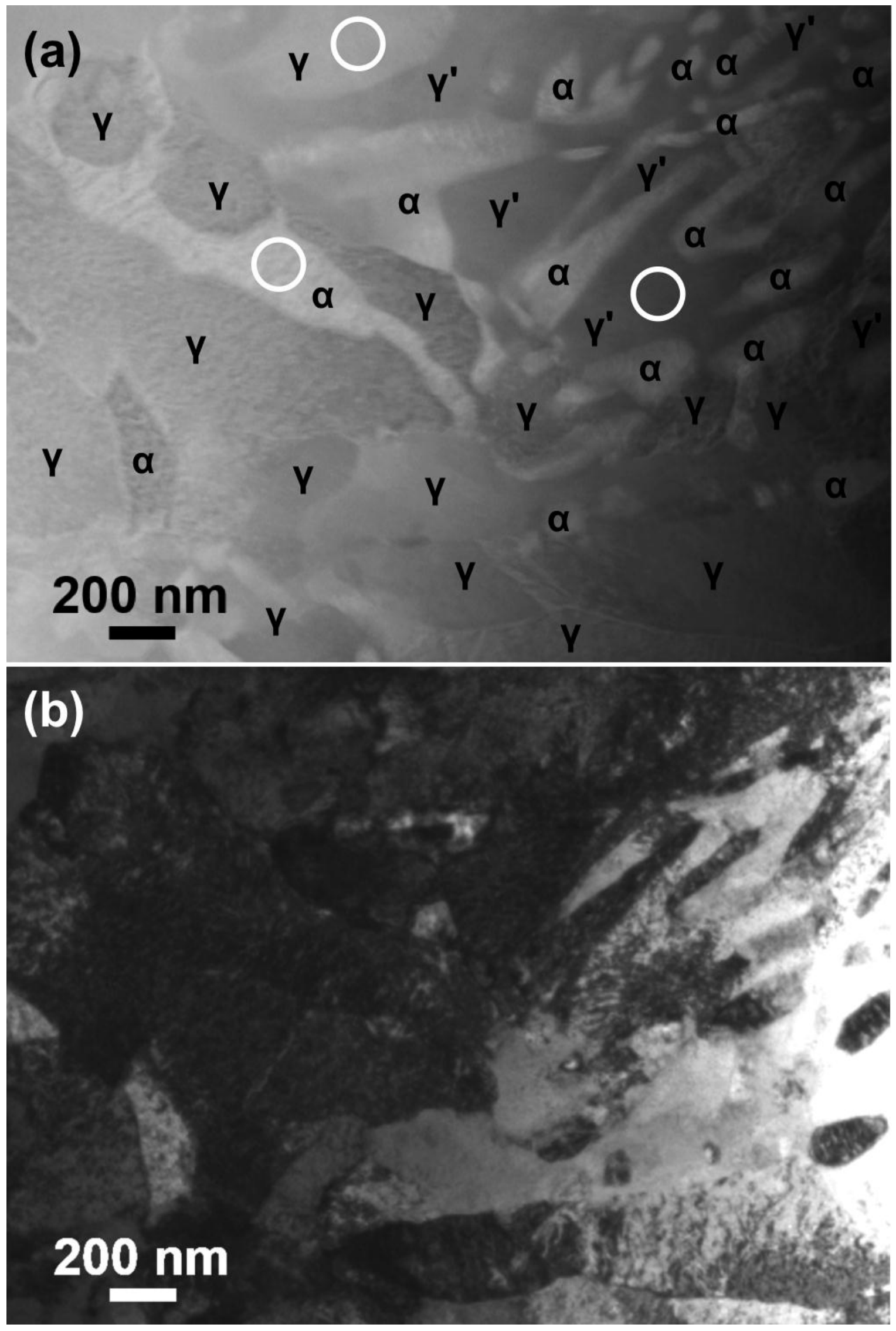


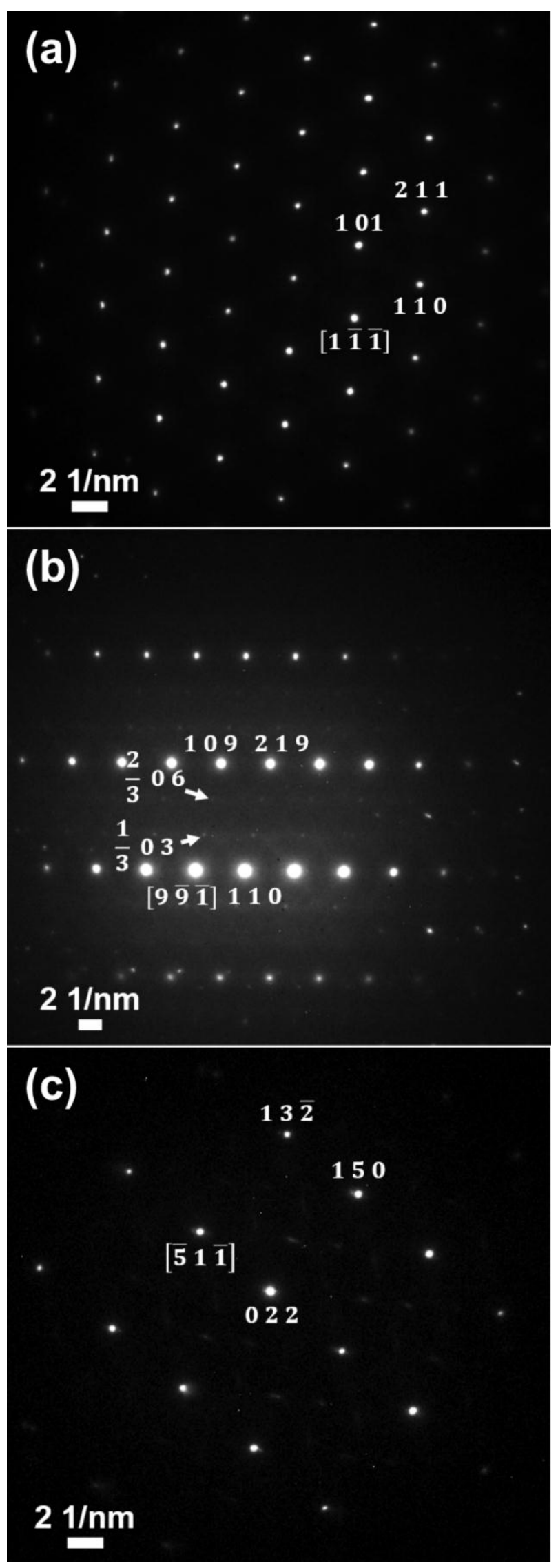




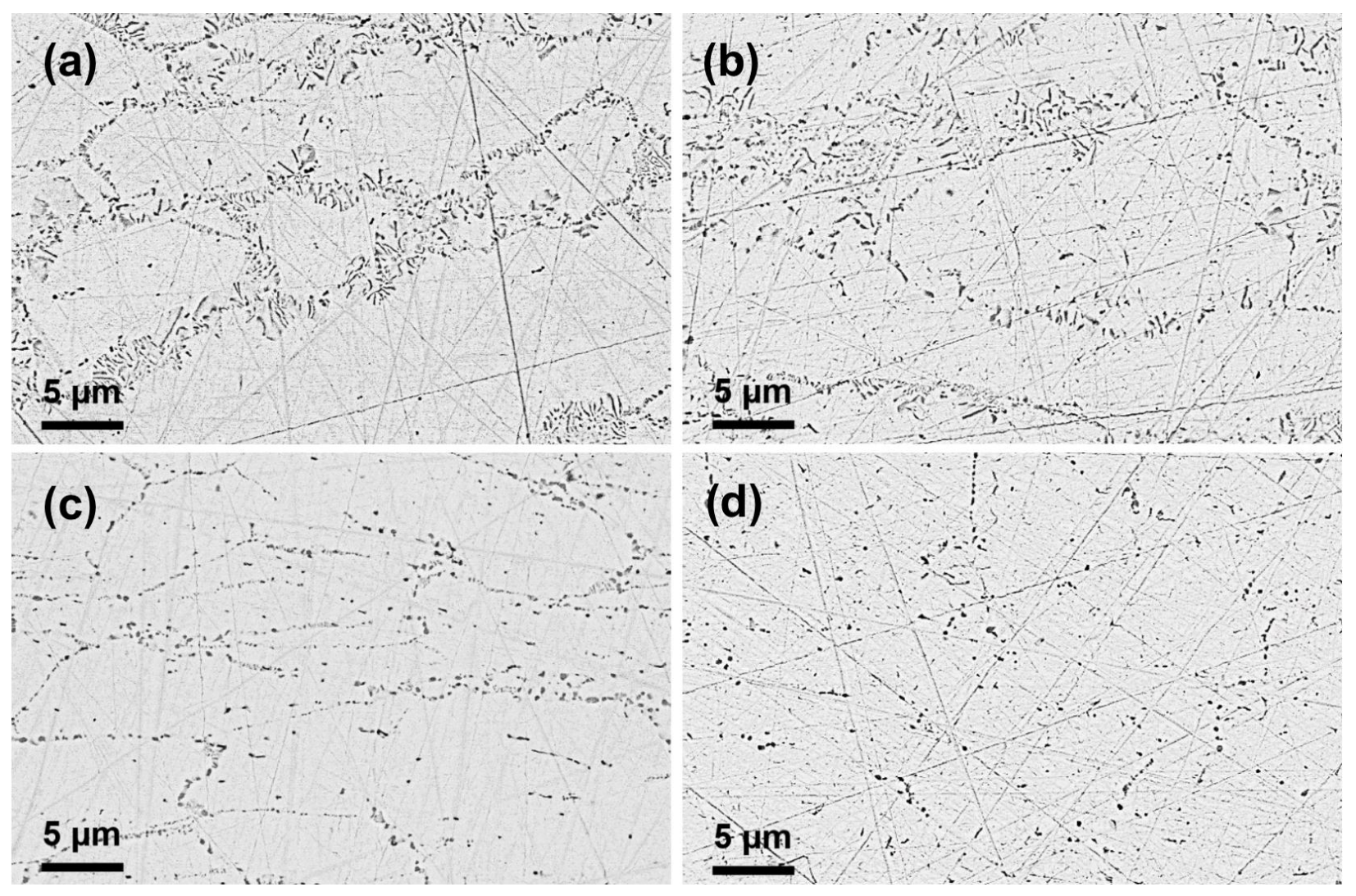




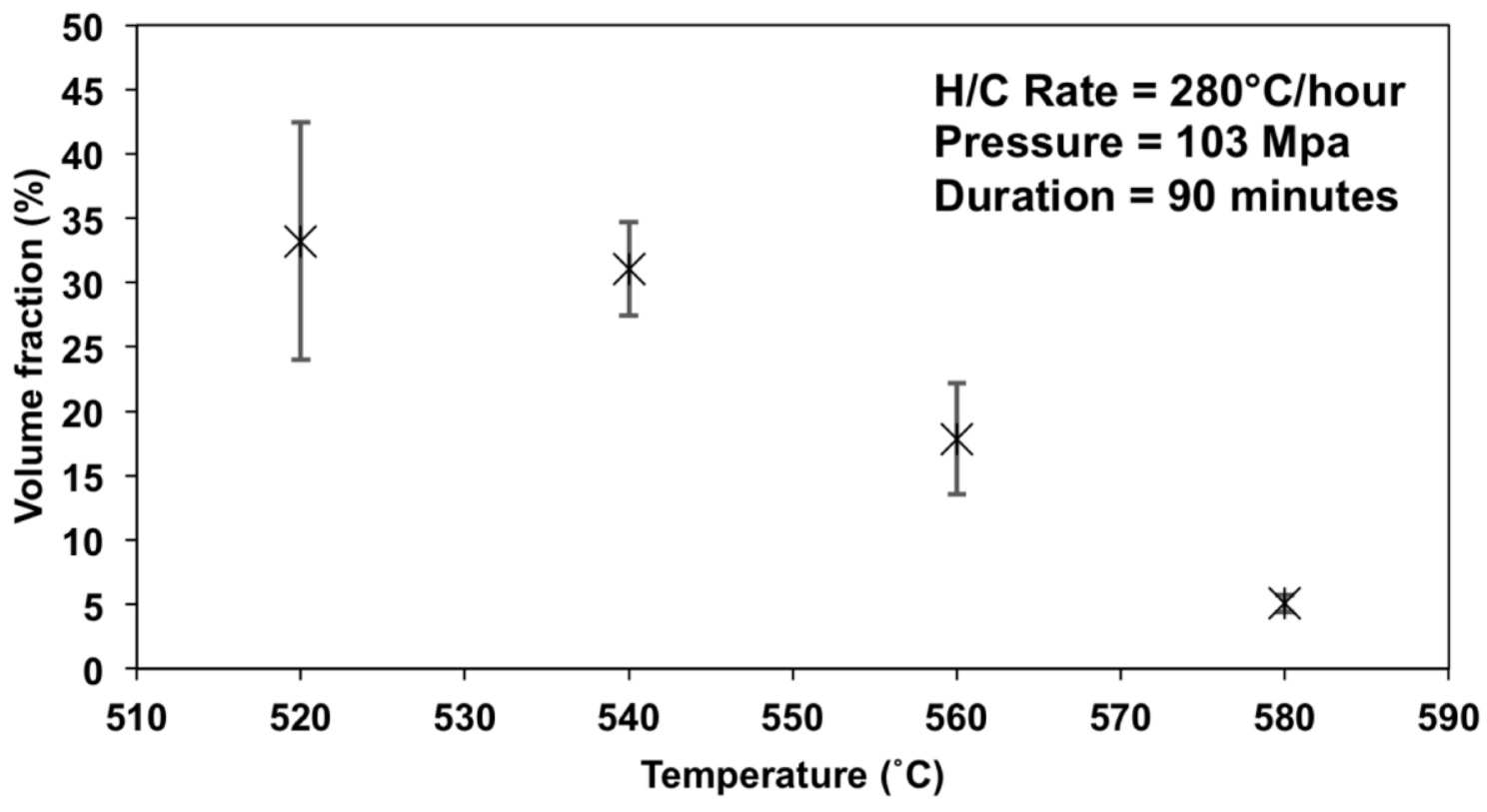




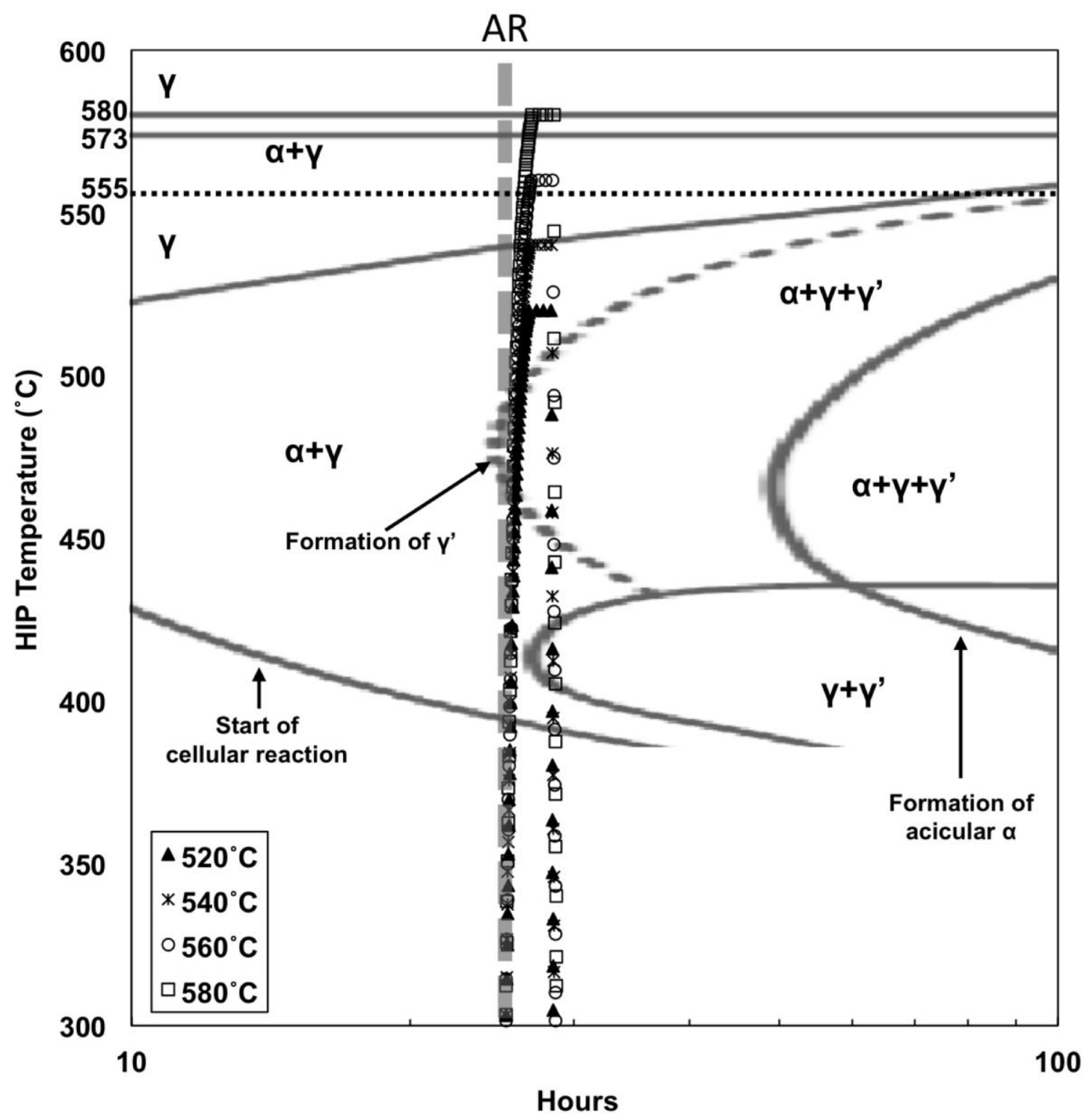




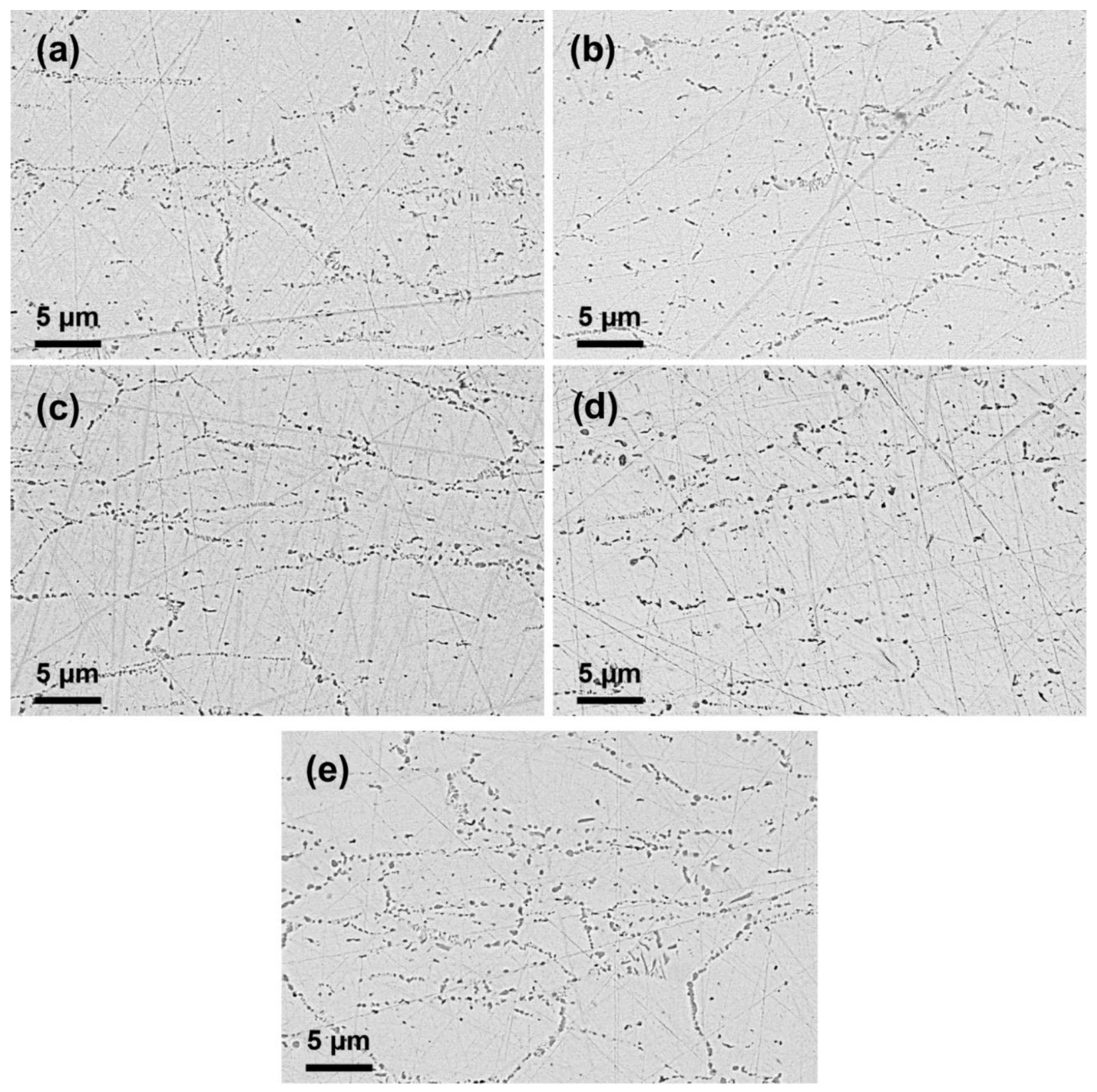




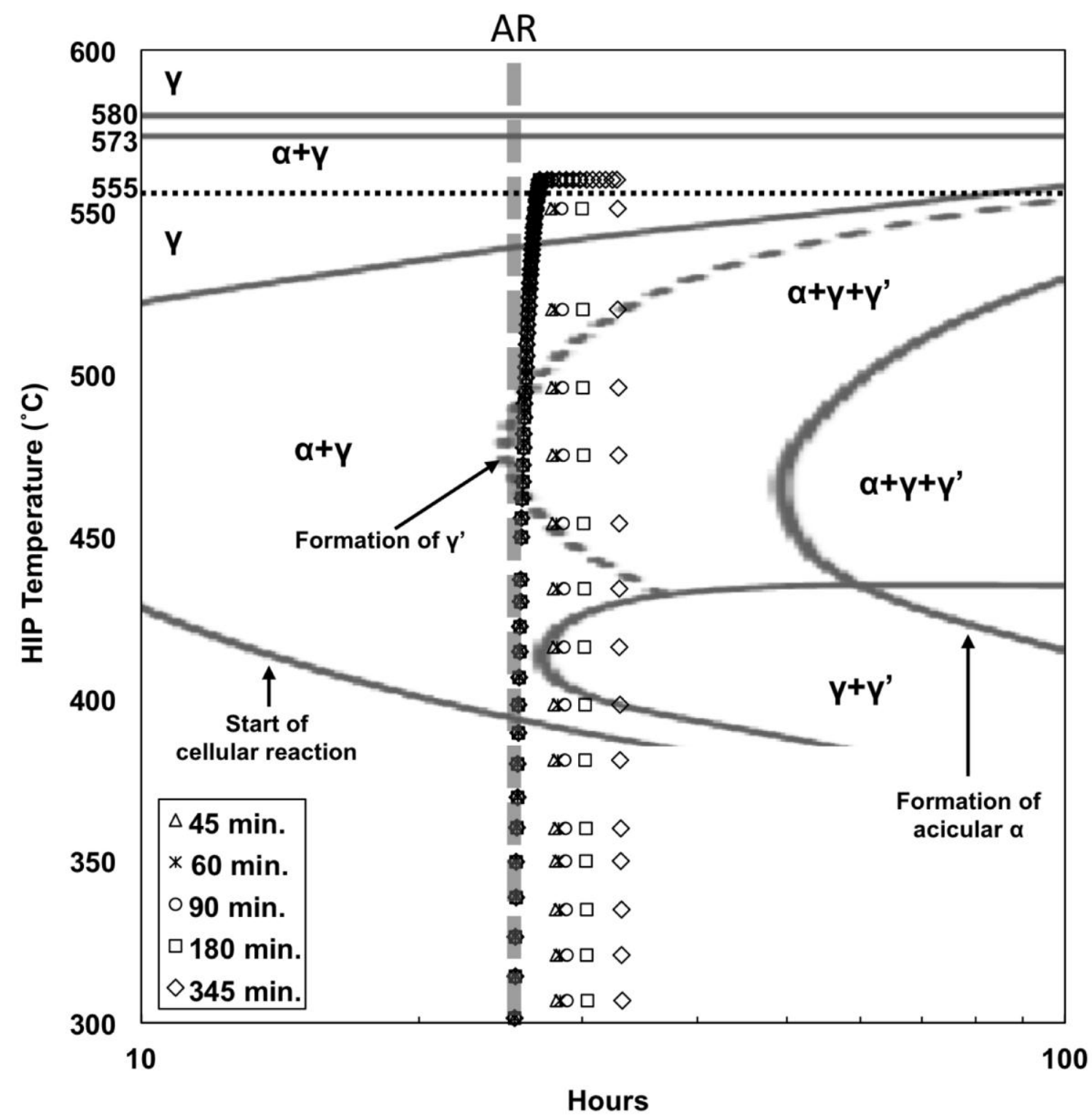




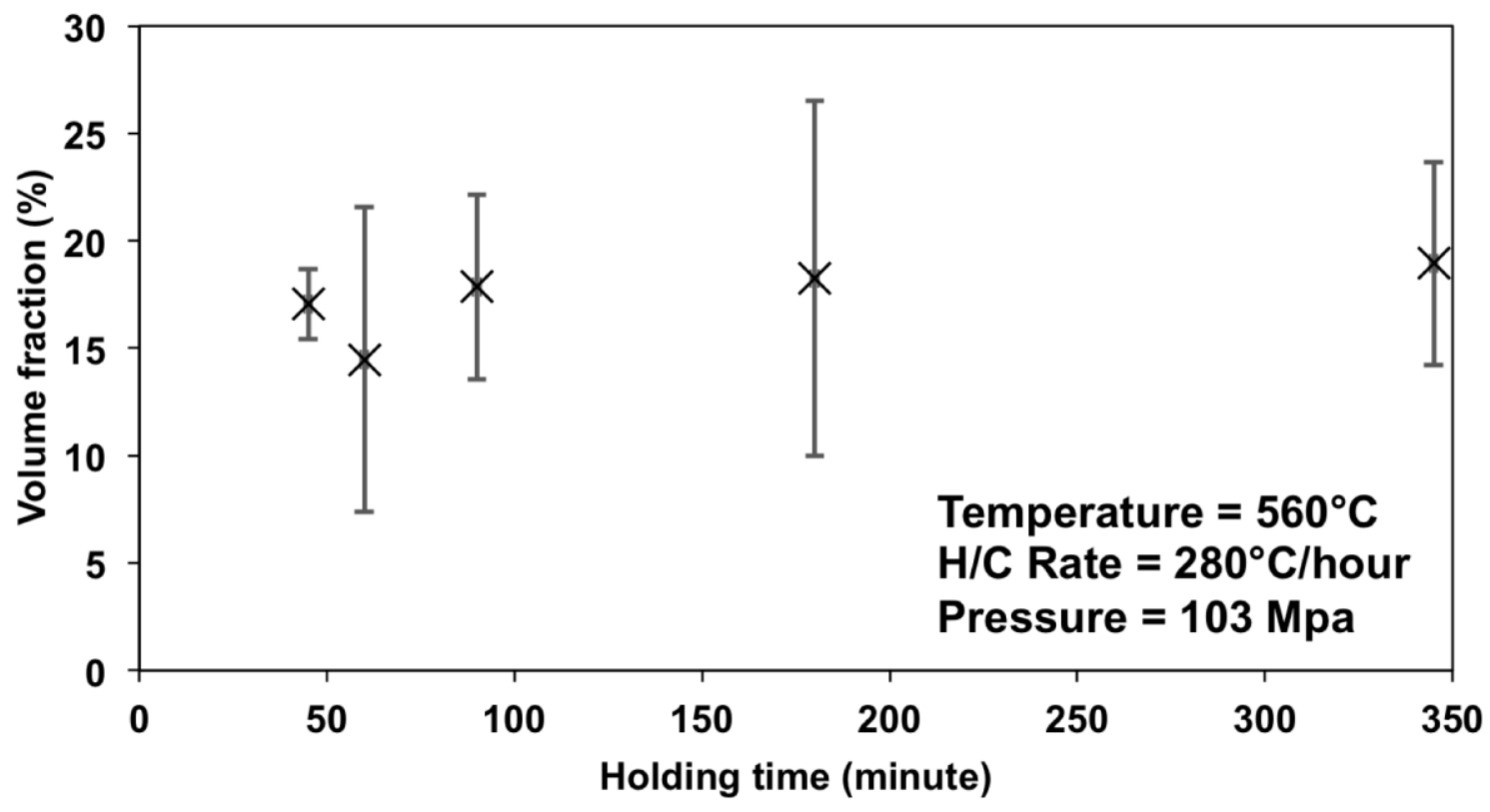




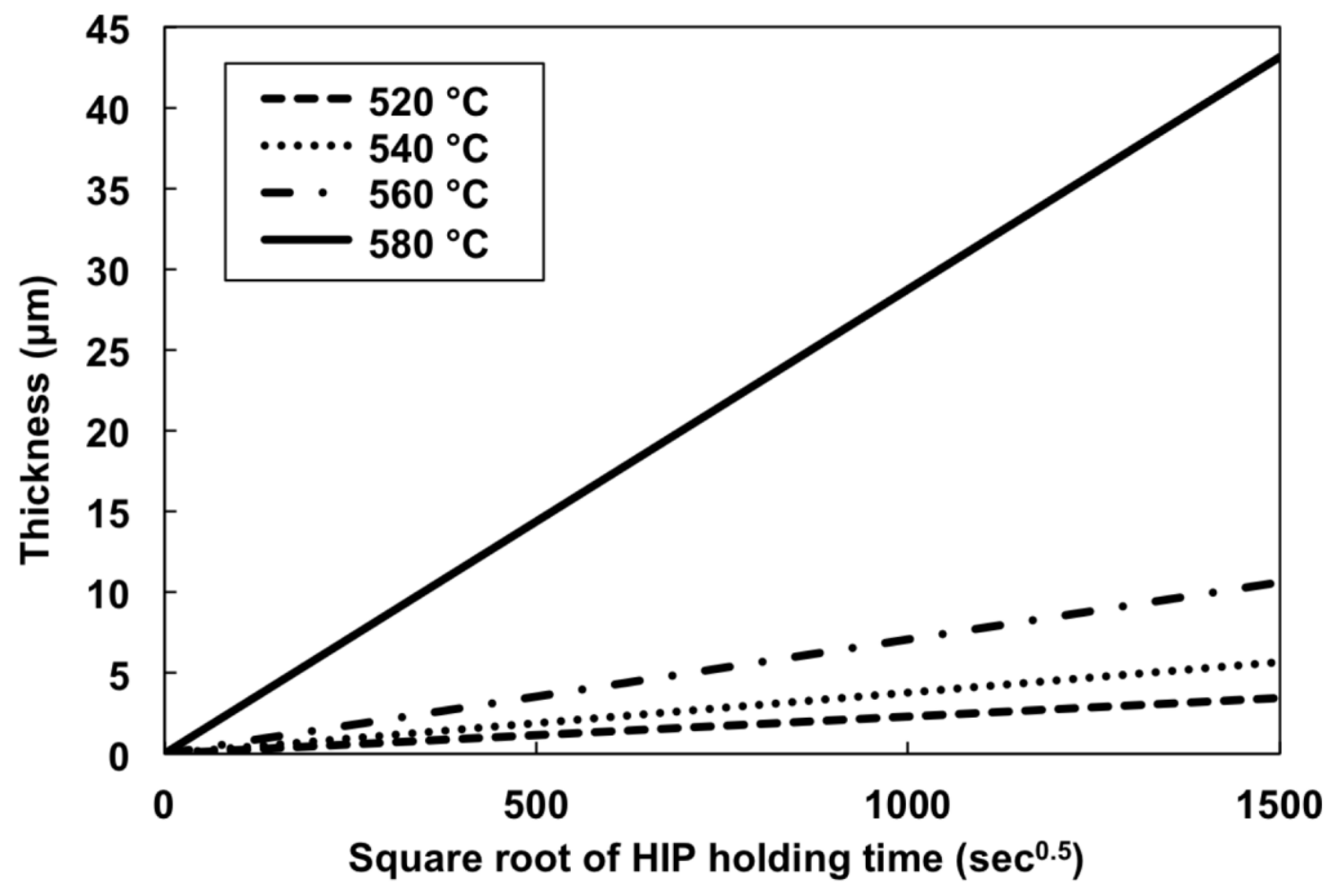


Table 1. Elemental characteristics of $\mathrm{Mo}, \mathrm{Zr}$ and $\mathrm{Nb}$ [42-44].

\begin{tabular}{|c|c|c|c|}
\hline Property & Mo & $\mathrm{Zr}$ & $\mathrm{Nb}$ \\
\hline Thermal neutron absorption (barn) & 2.48 & 0.18 & 1.15 \\
\hline Density $\left(\mathrm{gcm}^{-3}\right)$ & 10.22 & 6.49 & 8.35 \\
\hline Melting point $\left({ }^{\circ} \mathrm{C}\right)$ & 2623 & 1854 & 2477 \\
\hline Thermal expansion coefficient $\left(\mathrm{K}^{-1}\right)$ & $5.35 \times 10^{-6}$ & $5.78 \times 10^{-6}$ & $7.34 \times 10^{-6}$ \\
\hline Thermal Conductivity $\left(\mathrm{Wm}^{-1} \mathrm{~K}^{-1}\right)$ & 138 & 22.7 & 54 \\
\hline Corrosion resistance & Good & Good & Good \\
\hline
\end{tabular}


Table 2. Selected properties of $\gamma-U$ (U - 10 wt. $\%$ Mo), $\alpha-U$ and $\gamma^{\prime}-U_{2}$ Mo phases $[14,23,32,40$, 41, 45-52].

\begin{tabular}{|c|c|c|c|}
\hline Property & $\begin{array}{l}\gamma-(\mathrm{U} 10 \mathrm{Mo}) \\
\left(\text { at } 800{ }^{\circ} \mathrm{C}\right)\end{array}$ & $\begin{array}{c}\alpha-U \\
\left(\text { at } 627^{\circ} \mathrm{C}\right)\end{array}$ & $\begin{array}{l}\gamma^{\prime}-\left(\mathrm{U}_{2} \mathrm{Mo}\right) \\
\left(\text { at } 500{ }^{\circ} \mathrm{C}\right)\end{array}$ \\
\hline $\begin{array}{l}\text { Mo solubility } \\
\text { (Wt.\%) }\end{array}$ & 10 & 0.2 & 16 \\
\hline $\begin{array}{l}\text { Strukturbericht } \\
\text { designation }\end{array}$ & $\mathrm{A} 2$ & A20 & $\mathrm{C} 11 \mathrm{~b}$ \\
\hline Prototype & $\mathrm{W}$ & $\alpha-U$ & $\mathrm{MoSi}_{2}$ \\
\hline Crystal structure & $\begin{array}{l}\text { Body-centered } \\
\text { cubic }\end{array}$ & $\begin{array}{l}\text { C-centered } \\
\text { orthorhombic }\end{array}$ & $\begin{array}{l}\text { Body-centered } \\
\text { tetragonal }\end{array}$ \\
\hline \multirow{3}{*}{$\begin{array}{l}\text { Lattice parameter } \\
\qquad(\AA)\end{array}$} & 3.474 & 2.854 & 3.427 \\
\hline & 3.474 & 5.869 & 3.427 \\
\hline & 3.474 & 4.955 & 9.834 \\
\hline Space group & $\operatorname{Im} 3 m(229)$ & Cmcm (63) & $\mathrm{I} 4 / \mathrm{mmm}$ (139) \\
\hline Peason symbol & $\mathrm{cI} 2$ & oC4 & tI6 \\
\hline $\begin{array}{l}\text { Young's modulus } \\
\text { (GPa) }\end{array}$ & 98 & 117 & 102 \\
\hline $\begin{array}{l}\text { Hardness } \\
(\mathrm{GPa})\end{array}$ & 3.1 & 2.3 & N/R \\
\hline Poisson ratio & 0.35 & 0.26 & 0.40 \\
\hline $\begin{array}{l}\text { Thermal conductivity } \\
\qquad\left(\mathrm{W} \cdot \mathrm{m}^{-1} \mathrm{~K}^{-1}\right)\end{array}$ & 3.65 & 34 & N/R \\
\hline $\begin{array}{l}\text { Thermal expansion } \\
\text { coefficient }\left(10^{-6} \mathrm{~K}^{-1}\right)\end{array}$ & 19.2 & 18.0 & 14.7 \\
\hline $\begin{array}{l}\text { Specific heat } \\
\left(\mathrm{J} \cdot \mathrm{K}^{-1} \mathrm{~g}^{-1}\right)\end{array}$ & 0.194 & 0.192 & 0.154 \\
\hline
\end{tabular}


Table 3. Hot isostatic pressing parameters of monolithic fuel plate specimens examined in this study.

\begin{tabular}{|c|c|c|c|}
\hline $\begin{array}{c}\text { Sample } \\
\text { Identification }\end{array}$ & $\begin{array}{c}\text { Temp. } \\
\left({ }^{\circ} \mathrm{C}\right)\end{array}$ & $\begin{array}{c}\text { Hold Time } \\
(\text { min })\end{array}$ & $\begin{array}{c}\text { Ramp Rate } \\
\left({ }^{\circ} \mathrm{C} / \mathrm{hr}\right)\end{array}$ \\
\hline AR & N/A & N/A \\
\hline $52-90-280$ & 520 & 90 & 280 \\
\hline $54-90-280$ & 540 & 90 & 280 \\
\hline $56-90-280$ & 560 & 90 & 280 \\
\hline $58-90-280$ & 580 & 90 & 280 \\
\hline $56-45-280$ & 560 & 45 & 280 \\
\hline $56-60-280$ & 560 & 60 & 280 \\
\hline $56-180-280$ & 560 & 180 & 280 \\
\hline $56-345-280$ & 560 & 345 & 35 \\
\hline $56-90-35$ & 560 & 90 & 70 \\
\hline $56-90-70$ & 560 & 90 & 280 \\
\hline
\end{tabular}


Table 4. The critical temperature reported in literature [14,26,39] for $\alpha+\gamma^{\prime} \rightarrow \alpha+\gamma$ and $\alpha+\gamma \rightarrow$ $\gamma$ transitions in the $\mathrm{U}-10 \mathrm{wt}$ \% Mo alloy.

\begin{tabular}{|c|c|c|}
\hline & $\begin{array}{c}\alpha+\gamma^{\prime} \rightarrow \alpha+\gamma \\
\text { (lower critical temperature) }\end{array}$ & $\begin{array}{c}\alpha+\gamma \rightarrow \gamma \\
\text { (upper critical temperature) }\end{array}$ \\
\hline Repas [26] & $573^{\circ} \mathrm{C}$ & $580^{\circ} \mathrm{C}$ \\
\hline Kim [39] & $\mathrm{N} / \mathrm{R}$ & $>570$ \\
\hline Okamoto [13] & $555^{\circ} \mathrm{C}$ & $\sim 580^{\circ} \mathrm{C}$ \\
\hline
\end{tabular}

